SHORT COMMUNICATION

\title{
A study on post-harvest carotenogenesis of sweet potatoes under two different storage conditions
}

\author{
A.M.B. Priyadarshani, ${ }^{*}$ E.R. Jansz and H. Peiris \\ Department of Biochemistry, University of Sri Jayewardenepura, Gangodawila, Nugegoda.
}

Revised: 09 October 2006 ; Accepted: 16 March 2006

\begin{abstract}
In the context of prevention of vitamin A deficiency, the importance of orange-yellow fleshed sweet potato (Ipomoea batatas variety) has already been shown by many studies. In this study, the effect of storage on carotenogenesis was studied. The orange-yellow fleshed sweet potato variety, "Gannoruwa white" was stored under two different storage conditions namely (a) in the open air and (b) inside a Jute hessian (gunny) bag at ambient temperature for 12 days and carotenoid content was determined using HPLC on alternate days. Carotenogenesis occurred in both storage conditions with virtually no significant difference in $\beta$-carotene content between the two conditions after 12 days of storage. During open storage, the $\beta$-carotene content increased from $80.1 \mu \mathrm{g} / 100 \mathrm{~g}$ after day 1 of harvest to $172.5 \mu \mathrm{g} / 100 \mathrm{~g}$ at day 12 and in the Jute hessian bag storage, $\beta$ carotene content increased from $82.6 \mu \mathrm{g} / 100 \mathrm{~g}$ after day 1 of harvest to $188.0 \mu \mathrm{g} / 100 \mathrm{~g}$ at day 12 . Both expressed on the basis of dry weight. An unidentified carotenoid was the second highest whose spectral data corresponded to the $\alpha$-zeacarotene and high performance liquid chromatoghaphy (HPLC) retention time corresponded to lutein was showed the same trend of carotenogenesis as $\beta$-carotene. Carotenogenesis for 12 days increased $\beta$-carotene by $115 \%$ and $128 \%$ for the open air and the bag storage conditions, respectively.
\end{abstract}

Keywords: Ambient conditions, $\beta$-carotene, post-harvest carotenogenesis, sweet potato

\section{INTRODUCTION}

Micronutrient deficiency, particularly vitamin A deficiency is recognized as a public health problem in Sri Lanka ${ }^{1}$ as a result of low content of pre-formed vitamin A and provitamin $A$ carotenoids in the diets of the affected populations. There is an increasing interest in incorporation of pro-vitamin A carotenoid containing food into diets to alleviate vitamin A deficiency. Further, in addition to the well known pro-vitamin A activity of carotenoids, they have been implicated in the reduced risk of developing degenerative diseases ${ }^{2}$. The availability of orange-yellow fleshed sweet potatoes (Ipomoea batatas) in Sri Lanka has increased in recent years following its successful propagation and promotion by Agricultural authorities. The selection of sweet potato to study carotenogenesis was also opportune as it has a tuber that can be stored for more than 10 days without spoilage under ambient conditions. This is important as rural communities, which are most affected by vitamin A deficiency, have limited facilities for refrigeration. The objective of the present study was to determine postharvest carotenogenesis in sweet potato under ambient conditions stored in the open air, as well as in a Jute hessian (gunny) bag.

\section{METHODS AND MATERIALS}

Sweet potato (Ipomoea batatas) of the variety "Gannoruwa white" collected from the Horticultural Crop Research and Development Institute (HORDI) at Peradeniya was used in the study as it was available in large quantities grown under the same cultivation conditions. Tubers were harvested from the centre of each plot in morning (from 9 a.m. to $11 \mathrm{a} . \mathrm{m}$.). The plot sizes were approximately $1.5 \times 4 \mathrm{~m}$ each. The plots were about $0.5 \mathrm{~m}$ apart. From the intact tubers a sample was selected at random but for using a device to select only tubers below $\sim 4 \mathrm{~cm}$ diameter. Sample size was $20 \mathrm{~kg}$. This sample was then randomly grouped into two batches of $10 \mathrm{~kg}$ each. One sample was stored in a room (under the shade) and open to the atmosphere. The other sample was stored in a Jute hessian (gunny) bag under similar atmospheric conditions. Storage was at ambient temperature $\left(25-30^{\circ} \mathrm{C}\right)$ and relative humidity varying from 70 to $90 \%$. Storage period was 12 days. During open storage carotenoid 
content was determmed at day $1,2,4,7$ and 12 , whereas in the case of bag storage, analysis was done on day 1,3 , 5, 9 and 12 after harvest In each day, $2 \mathrm{~kg}$ lots were analysed individually, in duphcate The average weight of a tuber was $100 \mathrm{~g}$ and therefore, each $2 \mathrm{~kg}$ batch consisted of approximately 20 tubers Extraction was performed according to the procedure described by Rodrıguez-Amaya ${ }^{3} \quad \beta-A p o-8^{\prime}$ carotenal (trans) was employed as the internal standard

Caroteno1ds were separated in open column chromatography $(\mathrm{OCC})$, column prepared with $\mathrm{MgO}$ celite (1 1 activated at $110^{\circ} \mathrm{C}$ for 2$)^{3}$ Identification was based on scanning uv/visible spectrophotometry (Shimadzu model UV-1601), comparison of visible absorption spectra with the published spectral information $\left(\lambda_{\max }\right.$ and spectral fine structure), high performance liquid chromatoghaphy (HPLC) retention time and order of elution in $\mathrm{OCC}^{3}$ Identıty was confirmed using authentıc standards

Quantıfication was carried out by HPLC HPLC chromatographic conditions were similar to what has been described previously ${ }^{4}$ Precautıons were taken to mınımıze the losses of carotenoids during the analysis All experıments were conducted under dim light, samples were stored under nutrogen gas at $-20^{\circ} \mathrm{C}$ in amber bottles and experiments were completed within the shortest possible time Triplicate homogenızed samples $(5 \mathrm{~g})$ were freeze dried to constant weight to determine moisture content

\section{RESULTS AND DISCUSSION}

In sweet potato the major carotenold present was $\beta$ carotene The second height was an unidentified carotenold, which by spectral data corresponded to the $\alpha$-zeacarotene but HPLC retention time corresponded to luteın Relatıve changes accompanyıng in $\beta$-carotene content over 12 days storage in the open air and in the Jute hessian bag at ambient conditions are presented in Table 1 showing that enzymes responsible for the biosynthesis of carotenoids were apparently functioning normally under the storage conditions and carotenogenesis occurred durıng post-harvest storage $\beta$-carotene levels in the open and the bagged sample conditions on first day of harvest were $801 \mu \mathrm{g} / 100 \mathrm{~g}$ dry weight (DW) and $826 \mu \mathrm{g} / 100 \mathrm{~g} \mathrm{DW}$, respectively and these levels increased significantly with the storage, 22 and 23 fold for open and bagged samples respectively

Table 1: Changes in ${ }^{\text {a }}$ carotene and unidentıfied carotenoid of sweet potatoes durıng the open and the Jute hessian bag storage under ambient conditions

\begin{tabular}{|c|c|c|c|c|c|c|c|c|}
\hline \multirow{3}{*}{$\begin{array}{l}\text { Storage period } \\
\qquad \text { (days) }\end{array}$} & \multicolumn{4}{|c|}{$\hat{a}-$ Carotene $e^{a}$} & \multicolumn{4}{|c|}{ Unidentıfied carotenoid ${ }^{a}$} \\
\hline & \multicolumn{2}{|c|}{ Open } & \multicolumn{2}{|c|}{ Bagged } & \multicolumn{2}{|c|}{ Open } & \multicolumn{2}{|c|}{ Bagged } \\
\hline & Wet basis ${ }^{b}$ & Dry basıs ${ }^{\mathfrak{C}}$ & Wet basis ${ }^{b}$ & Dry basis ${ }^{\mathfrak{c}}$ & Wet basis ${ }^{b}$ & Dry basis ${ }^{\mathrm{c}}$ & Wet basis ${ }^{b}$ & Dry basis ${ }^{c}$ \\
\hline 1 & 222 & 801 & 228 & 826 & 83 & 299 & 751 & 272 \\
\hline 2 & 367 & 1192 & & - & 116 & 356 & & - \\
\hline 3 & - & & 32.2 & 1154 & - & - & 101 & 362 \\
\hline 4 & 431 & 1368 & - & - & 154 & 488 & & - \\
\hline 5 & & - & 416 & 1470 & - & - & 117 & 413 \\
\hline 6 & - & - & - & - & & - & & - \\
\hline 7 & 487 & 1480 & - & & 213 & 647 & - & - \\
\hline 8 & - & - & - & - & & - & & \\
\hline 9 & & - & 507 & 1779 & - & - & 183 & 642 \\
\hline 10 & - & - & - & - & & - & & \\
\hline 11 & & - & & - & - & - & - & - \\
\hline 12 & 595 & 1725 & 549 & 1880 & 252 & 730 & 237 & 812 \\
\hline
\end{tabular}

${ }^{\mathrm{a}}$ Values given $1 \mathrm{~g} / 100 \mathrm{~g}$

${ }^{b}$ Analysed by HPLC in duplicate

${ }^{\circ}$ Calculated from wet basis and moisture content 
The normalcy of biosynthesis is further substantiated by the unidentified carotenoid, increasing by the same magnitude (2.4 and 3.0 fold for open and bagged samples, respectively). The possible effect of different maturity stages of tubers on $\beta$-carotene concentration was overcome as each lot analysed contained many tubers ( $\sim 20$ tubers) and the sample taken for the analysis was drawn after the edible part was chopped into very small pieces and then mixing thoroughly. The adequacy of sampling was reflected by the $\beta$-carotene content in the samples analysed on the first day of harvest (22.2 and $22.8 \mu \mathrm{g} / 100 \mathrm{~g}$ fresh weight for open and gunny bag storage respectively). In the study, factors that can affect carotenoid content in plant foods were minimized keeping the two different storage conditions' as the only variable.

In addition to the post-harvest carotenogenesis, the degradation of the carotenoids also can occur during postharvest storage, especially at elevated temperature and due to the enzymatic oxidation. But in the present study, concentrations of the $\beta$-carotene and the absence of enzymatic oxidation products of $\beta$-carotene showed that this did not happen. The study showed that in orangeyellow sweet potato carotenogenesis causes pro-vitamin A activity to rise more than two fold.

No comparison can be made with previous studies because the storage conditions of various studies were different to that of the present study, e.g. storage effect of raw spinach, carrots, green beans and broccoli were conducted under refrigerated conditions ${ }^{5,6}$. A study carried out on African mangoes stored at tropical ambient conditions showed the effect of post-harvest temperature on ripening of this fruit ${ }^{7}$ but this is not relevant to sweet potatoes as the yam does not ripe. The only similar study was on pumpkin, stored under the same conditions (open storage) for three months showed $1263 \%$ increase of $\beta$ carotene but sampling procedure was not clear in that study.

\section{CONCLUSION}

Fresh, intact sweet potatoes could be stored in the open air or in a gunny bag for 12 days after harvest under ambient conditions with no signs of spoilage. Such storage can elevate pro-vitamin A carotenoid content ( $\beta$ carotene) by more than two fold due to carotenogenesis. This information is of importance to rural Sri Lankans consuming sweet potato.

\section{Acknowledgement}

The authors thank IPICS SRI: 07 for a grant.

\section{References}

1. MRI (1998). Report of the survey on vitamin A deficiency status of children in Sri Lanka 1995/96. Funded by the United Nations Children's Fund. Medical Research Institute, Colombo 8.

2. Rock C.L. (1997). Carotenoids: biology and treatment. pharmacology therapy 75 (3): 185-197.

3. Rodriguez-Amaya D.B. (1999). A Guide to carotenoid analysis in foods. International Life science Institute, Washington, DC.

4. Priyadarshani A.M.B. \& Jansz E.R. (2006). The effect of maturity on carotenoids of Lasia spinosa stem and the effect of cooking in-vitro bioaccessibility of carotenoids. Journal of the National Science Foundation 34 (3): 131-136.

5. Kopas-Lane L.M. \& Warthesen J.J. (1995). Carotenoid photostability in raw spinach and carrots during cold storage. Journal of Food Science 60 (4): 773-834.

6. Rodriguez-Amaya D.B. (1997). Carotenoids and food preparation: The retention of pro- vitamin A carotenoids in prepared, processed and stored food. United States Agency for International Development.

7. Aina J.O. (1990). Physico-chemical changes in African mango (Irivingia gabonensis) during normal storage ripening. Food Chemistry 36: $205-212$.

8. Chavasit V., Pisaphab R., Sungpuag P., Jittinandana S. \& Wasantwisut E. (2002). Changes in $\hat{a}$-carotene and vitamin $A$ contents of vitamin A-rich foods in Thailand during preservation and storage. Journal of Food Science 67:375-379. 